\title{
Atrial Thrombus
}

National Cancer Institute

\section{Source}

National Cancer Institute. Atrial Thrombus. NCI Thesaurus. Code C111118.

Presence of a blood clot in the atria of the heart. 